\title{
Cell-specific expression of NADPH-dependent cytosolic 3,5,3'-triiodo-L-thyronine-binding protein (p38CTBP)
}

Satoru Suzuki, Jun-ichirou Mori, Mutsuhiro Kobayashi ${ }^{1}$, Takeshi Inagaki, Hidefumi Inaba, Ai Komatsu, Koh Yamashita, Teiji Takeda, Takahide Miyamoto, Kazuo Ichikawa and Kiyoshi Hashizume

Department of Aging Medicine and Geriatrics, Shinshu University School of Medicine, 3-1-1, Asahi, Matsumoto, Nagano 390-8621, Japan and ${ }^{1}$ Iida Municipal Hospital, 438, Yawata, Iida 395-0814, Japan

(Correspondence should be addressed to Satoru Suzuki; Email: soutaro@hsp.md.shinshu-u.ac.jp)

\begin{abstract}
We have previously shown that cytosolic 3,5,3'-triiodo-L-thyronine (T3)-binding protein (CTBP) possesses a high affinity for $\mathrm{T} 3$ binding in the presence of nicotinamide adenine dinucleotide phosphate in vitro, and that p38CTBP increases intracellular content of T3, and suppresses T3-mediated transactivity. Screening of mRNA expression in 73 different human tissues has demonstrated that p38CTBP mRNA is expressed at high levels in brain and heart. We have examined the intracellular localization and tissue-specific distribution of this protein by using a specific antibody against human p38CTBP. Western blotting and immunoprecipitation studies have shown that the antibody recognizes human p38CTBP. Interaction of p38CTBP with the antibody did not affect the T3-binding activity of $\mathrm{p} 38 \mathrm{CTBP}$, and its dimer formation in vitro. Western blotting analysis has shown that p38CTBP is expressed in brain and heart predominantly, similar to the distribution of mRNA. Immunohistochemical studies have demonstrated p38CTBP in neural cells and cardiac muscle cells. p38CTBP localizes in cytoplasm rather than in nuclei in neural cells. The evidence for the presence of tissue-specific localization of $\mathrm{p} 38 \mathrm{CTBP}$ has indicated that $\mathrm{p} 38 \mathrm{CTBP}$ has a tissue-specific function, such as the regulation of T3 delivery from cytoplasm to nuclei.
\end{abstract}

European Journal of Endocrinology 148 259-268

\section{Introduction}

Thyroid hormone regulates multiple cellular events, including energy expenditure and cellular differentiation (1). Although it is well known that the action of thyroid hormone is initiated through the activation of gene expression by binding to its nuclear receptor (2), the mechanism of the transport of the hormone to nuclei from cytoplasm is not certain $(3-5)$.

We have previously demonstrated that nicotinamide adenine dinucleotide phosphate (NADPH)-dependent cytosolic 3,5,3'-triiodo-L-thyronine (T3)-binding protein (CTBP) contributes to intracellular storage and translocation of T3 in vitro $(6-10)$. We have identified two CTBPs from rat kidney and liver. One was $4.7 \mathrm{~S}$ CTBP (p58CTBP) and the other was 5.1S CTBP, which consisted of a dimer of $38 \mathrm{kDa}$ polypeptide (p38CTBP) (11). Each dimer or monomer was activated by $\mathrm{NADPH}$. In the presence of NADPH, the affinity constant of T3 binding was $2 \times 10^{9} \mathrm{~mol} / \mathrm{l}$, which was similar to that of nuclear T3 receptors, indicating that CTBP may play a physiological role in thyroid hormone action in its target tissues.
Maximal binding capacity (MBC) also increased by activation with NADPH. In studies with rats, the MBC obtained in the presence of NADPH increased during the growth of animals, and a tissue-specific increase was observed $(12,13)$. Cellular levels of the protein could be increased by thyroid hormone, vitamin D3 and insulin in vitro (14-17). Dexamethasone increases the mRNA of CTBP in cultured human myeloblasts (18). Butyrate, which also induces deacetylation of histone, increases the activity of CTBP in primary cultures of rat hepatic cells (19). These results indicate that the activity of this protein is regulated by multiple factors (20).

It was recently demonstrated that p38CTBP was identical to $\mu$-crystallin in studies with the determination of the amino acid sequence of the protein (21). The $\mu$-crystallin protein, a taxon-specific $35 \mathrm{kDa}$ protein that is highly expressed in lens (22), brain, muscle and kidney in the kangaroo (23), may be important in maintaining structural function in these tissues of the kangaroo. Kim et al. (23) also reported the cloning of $\mu$-crystallin cDNA from human retina and showed that it was expressed at high levels in human neural tissue, muscle and kidney. The expression 
of p38CTBP increased not only cytoplasmic but also nuclear content of T3, while it suppressed T3-mediated transactivation in CTBP-expressing stable GH3 cell lines, implying that p38CTBP regulates $\mathrm{T} 3$ content and T3-induced transactivation in tissues (24).

In this study, we have characterized the antibody against human p38CTBP, which was raised previously, in vitro. By using this antibody, intracellular localization of p38CTBP was assessed and we estimated the tissuespecific localization of this protein. We obtained results showing that the protein is distributed in various human tissues in a cell-specific manner.

\section{Materials and methods}

\section{Cloning of human p38CTBP and construction of plasmids}

Full-length human p38CTBP cDNA was amplified by PCR as described previously (24). The amplified fragment was cloned into the TA cloning site of pT7-Blue (Novagen, Madison, WI, USA). The BamHIHindIII fragment was cloned into pQBI-25-fc2 (Quantam Biotechnologies Inc, Quebec, Canada) vector which induces green fluorescent protein (GFP)-tagged CTBP in mammalian cells. The BamHI-SalI fragment of pT7-CTBP was ligated into pcDNA3.1 (Invitrogen, Carlsbad, CA, USA), which is available for the expression in mammalian cells and in vitro transcription and translation. The EcoRI-SalI fragment was inserted into the same sites of pGEX-6p-3 (Amersham Pharmacia Biotech, Amersham, Bucks, UK). pGEX-CTBP is expressed as GST-tagged CTBP in E. coli strain BL21.

\section{Establishment of p38CTBP-expressing CHO cell lines (CPC45)}

CPC45, in which GFP-tagged p38CTBP is expressed, was established as previously described (24).

\section{Preparation of polyclonal antibodies to p38CTBP (CTBP168)}

Synthetic peptides containing a part of the human p38CTBP amino acid sequence were used in the immunization as described previously (24). The amino acid sequence (CNRTKENAEKFADTV) was chosen because of its high antigenicity index, determined by Epitope Adviser (Fujitsu, Shizuoka, Japan). Antibodies were raised in rabbits obtained from Takara Inc, Ohtsu, Japan. The antibody was purified by affinity column chromatography with the immunized peptide.

\section{Detection of $338 \mathrm{CTBP}$ with antibody}

Immunoprecipitation of p38CTBP expressed in reticulocyte lysate was performed as follows. $\left[{ }^{35} \mathrm{~S}\right]$ Methioninelabeled p38CTBP was expressed in the TNT Coupled
Reticulocyte Lysate System (Promega, Madison, WI, USA). An aliquot $(1 \mu \mathrm{l})$ containing radioactive p38CTBP translated in vitro was incubated for $2 \mathrm{~h}$ at $4{ }^{\circ} \mathrm{C}$ with $10 \mu \mathrm{l}(9 \mu \mathrm{g}) \mathrm{CTBP} 168$ or rabbit polyclonal anti-human Fas antibody as a negative control antibody in $1 \mathrm{ml}$ TBSD buffer $(10 \mathrm{mmol} / \mathrm{l}$ Tris $-\mathrm{HCl}, \mathrm{pH}$ 7.6, $100 \mathrm{mmol} / \mathrm{l} \mathrm{NaCl}$ and $1 \mathrm{mmol} / \mathrm{l}$ dithiothreitol (DTT)), containing $1 \%$ bovine serum albumin and $0.05 \%$ Triton X-100. Incubation was continued further for $30 \mathrm{~min}$ at $4^{\circ} \mathrm{C}$ after adding $10 \mu \mathrm{l}$ protein A (recombinant)-agarose (Upstate Biotechnology, Lake Placid, NY, USA). The mixture was centrifuged at $1500 \boldsymbol{g}$ for $5 \mathrm{~min}$, and the resultant pellet was washed twice with $1 \mathrm{ml}$ of the same buffer. The final pellet obtained was applied to SDS-PAGE, and autoradiography was performed by the bio-imaging analyzer BAS-1500 (Fuji, Chiryuh, Japan).

Western blotting of p38CTBP was performed as previously described (24). Briefly, cells were washed twice in ice-cold phosphate-buffered saline (PBS) and lysed by adding lysis (RIPA) buffer (0.05\% SDS, $1 \%$ Nonidet $\mathrm{P}-40,150 \mathrm{mmol} / \mathrm{l} \mathrm{NaCl}, 50 \mathrm{mmol} / \mathrm{l}$ Tris-HCl, $\mathrm{pH} 7.2$, containing $1 \mathrm{mmol} / \mathrm{l}$ phenylmethylsulfonyl fluoride). Proteins were resuspended in lysis buffer containing $2 \%$ SDS, and samples were separated in 10\% SDSPAGE gels and transferred to immobilon-P membranes (Millipore, Bedford, MA, USA). The membranes were blocked with TBS-T (100 mmol/l NaCl, $10 \mathrm{mmol} / \mathrm{l}$ Tris-HCl, pH 7.5 and $0.1 \%$ Tween 20) containing $1 \%$ skim milk. Prior to blocking experiments, CTBP168 antibody $(10 \mu \mathrm{l})$ was incubated with $0.5 \mathrm{mg}$ of the blocking peptide in $5 \mathrm{ml}$ TBS-T containing 1\% skim milk at $4^{\circ} \mathrm{C}$ for $18 \mathrm{~h}$. Detection was carried out by measuring the enhanced chemiluminescence using a horseradish peroxidase (HRP)-coupled mouse-anti-goat IgG antibody (Amersham, Arlington Heights, IL, USA).

\section{Estimation of effect of antibody on the function of $\mathrm{p} 38 \mathrm{CTBP}$}

Estimation of the effect of antibody on the dimerization of p38CTBP was performed by using a GST pull-down assay as previously described (25). Briefly, the bacterial pellet was resuspended in $600 \mu \mathrm{l}$ ice-cold PBS containing $0.05 \%$ Triton X-100 and 1mmol/l DTT (PBS-TD). After sonication and centrifugation, the supernatant was incubated with $10 \mu \mathrm{l}$ GST-Sepharose beads (Amersham Pharmacia Biotech) for $30 \mathrm{~min}$ at $4{ }^{\circ} \mathrm{C}$. Coated beads were washed twice with PBS-TD, and incubated with $\left[{ }^{35}\right.$ S $]$ methionine-labeled p38CTBP with or without various concentrations of anti-p38CTBP antibody (CTBP168) in $200 \mu \mathrm{l}$ TEND (50 mmol/l Tris-HCl, pH 7.6, $100 \mathrm{mmol} / \mathrm{l} \mathrm{NaCl}, 1 \mathrm{mmol} / \mathrm{l}$ EDTA and $1 \mathrm{mmol} / \mathrm{l}$ DTT) for $6 \mathrm{~h}$ at $4{ }^{\circ} \mathrm{C}$. The mixtures were centrifuged, and the pellet was washed three times with TEND, and proteins were separated by SDS-PAGE. Radioactivity was quantified by using the BAS-1500. 
The effect of antibody on T3 binding was estimated as follows. Fractions ( $5 \mu \mathrm{l}$ ) containing p38CTBP, expressed in the TNT Coupled Reticulocyte Lysate System, were incubated for $24 \mathrm{~h}$ at $4{ }^{\circ} \mathrm{C}$ with various amounts of CTBP168 or with rabbit polyclonal anti-human FAS antibody (Santa Cruz Biotechnology, Santa Cruz, CA, USA) as a negative control antibody in a final volume of $200 \mu \mathrm{l}$ with TBSD buffer, containing [ [ $\left.{ }^{125} \mathrm{I}\right] \mathrm{T} 3$ $(2250-3300 \mu \mathrm{Ci} / \mu \mathrm{g})$ and $100 \mu \mathrm{mol} / \mathrm{l}$ NADPH. After appropriate incubation times, bound and free hormones were separated by dextran-coated charcoal as described (6).

\section{Detection of p38CTBP RNA in human tissues}

The cDNA fragments of human p38CTBP were isolated from pT7-CTBP. Hybridization with a ${ }^{32}$ P-labeled fragment of CTBP cDNA was performed by using Human RNA Master Blot membrane, purchased from Clontech Inc. (Palo Alto, CA, USA), according to the manufacturer's protocol. This commercial dot blot contains poly $^{+}$mRNA, and has been normalized by the manufacturer using a range of housekeeping genes. The autoradiographic signals were quantitated by the BAS-1500.

\section{Immunohistochemistry}

Human tissue sections were purchased from Novagen (Madison, WI, USA). Sections were dewaxed, rehydrated, and endogenous peroxidase was blocked by using $0.3 \% \mathrm{H}_{2} \mathrm{O}_{2}$ in methanol. After washing with PBS, sections were reacted with primary antibody (CTBP168; 1:100 dilution) overnight at $4^{\circ} \mathrm{C}$. For competition studies, CTBP168 was preabsorbed by the immunizing peptide $(100 \mu \mathrm{g} / \mathrm{ml}$ in final concentration) overnight at $4{ }^{\circ} \mathrm{C}$. As a control, the same concentration of non-specific peptide was added. After washing with PBS, sections were incubated with HRP-labeled-goat anti-rabbit IgG (1:100 dilution) for $2 \mathrm{~h}$ at room temperature. After washing with PBS, the HRP sites were visualized by $3-3^{\prime}$ diaminobenzidine, $\mathrm{H}_{2} \mathrm{O}_{2}, \mathrm{Co}^{2+}$ and $\mathrm{Ni}^{+}$. Rodamine-labeled-goat anti-rabbit IgG (DAKO, Carpineria, CA, USA) was used as the second antibody in some experiments. The nuclei were stained with 4',6-diamidine-2'-phenylindole dihydrochloride (DAPI) in methanol. After washing with PBS, the sections were mounted with Slow-Fade (Molecular Probes, Eugene, OR, USA). Photographs were taken at $\times 100$ or $\times 400$ magnification.

\section{Results}

\section{Tissue-specific expression of p3 8CTBP mRNA in the human}

mRNA of p38CTBP was expressed in various tissues in the human (Fig. 1). Brain, heart and pituitary were tissues which expressed mRNA highly. Relatively high expression was observed in kidney, prostate and salivary glands. However, minimal expression was detected in the gastrointestinal tract, immune system (including spleen), lung, placenta, thyroid glands and pancreas. Although high expression was observed in the brain, it was heterogeneous. Cerebral cortex, cerebellum, amygdala, caudate nucleus, hippocampus, putamen and accumbens were the sites of highest expression. In contrast to these regions, expression was not high in pons, corpus callosum, medulla oblongata, substantia nigra, thalamus and spinal cord. Expression in the fetus was low even in heart and brain. The human cancer cells studied did not show expression.

\section{Characterization of anti-p 38 CTBP antibody (CTBP168)}

As shown in Fig. 2A (left panel), fluoroscopic examination detected the fluorescent signals in the cytoplasm of $\mathrm{CPC} 45$ cells which permanently express the GFP-p38CTBP fusion protein in CHO-K1 cells. The calculated molecular mass of GFP-fused p38CTBP is $66 \mathrm{kDa}$. Western blotting demonstrated that CTBP168, an anti-p38CTBP antibody, recognized a $66 \mathrm{kDa}$ protein in the CPC45 but not in CHO-K1 cells. Pre-absorption of the antibody with the immunized peptide caused the recognizing activity to disappear (Fig. 2A, right panel). The antibody (CTBP168), in addition to recognition of the fusion protein, was able to immunoprecipitate $\left[{ }^{35} \mathrm{~S}\right]$-labeled p38CTBP expressed in the reticulocyte lysate (Fig. 2B). However, the radioactive protein was not detected by protein agarose $\mathrm{A}$ alone or rabbit antiFas polyclonal antibody which was chosen as one of the negative control antibodies (Fig. 2B). Since we observed NADPH-dependent T3-binding activity in the reticulocyte lysate, the antibody (CTBP168) raised by our system recognized not only GFP-fused p38CTBP but also native (non-denatured) p38CTBP.

CTBP168, an anti-p38CTBP antibody, did not inhibit the NADPH-dependent T3 binding activity of the p38CTBP expressed in reticulocyte lysate (Fig. 2C). Further, we observed that the p38CTBP- $\left[{ }^{35} \mathrm{~S}\right]$ p38CTBP interaction was not modified by the antibody in studies with the GST pull-down assay (Fig. 2D). These results indicated that the antibody influenced neither T3 binding nor dimerizing activity of the p38CTBP.

\section{Tissue-specific expression of $38 \mathrm{CTBP}$ in the human}

Expression of p38CTBP was estimated by Western blotting. As shown in Fig. 3, the protein was predominantly expressed in brain and heart. Tissuespecific distribution of p38CTBP was evaluated by an immunohistochemical technique, using CTBP168 as an anti-p38CTBP antibody. p38CTBP was preferentially expressed in neurons in the cerebral cortex (Fig. 4a). In order to evaluate the intracellular localization of 


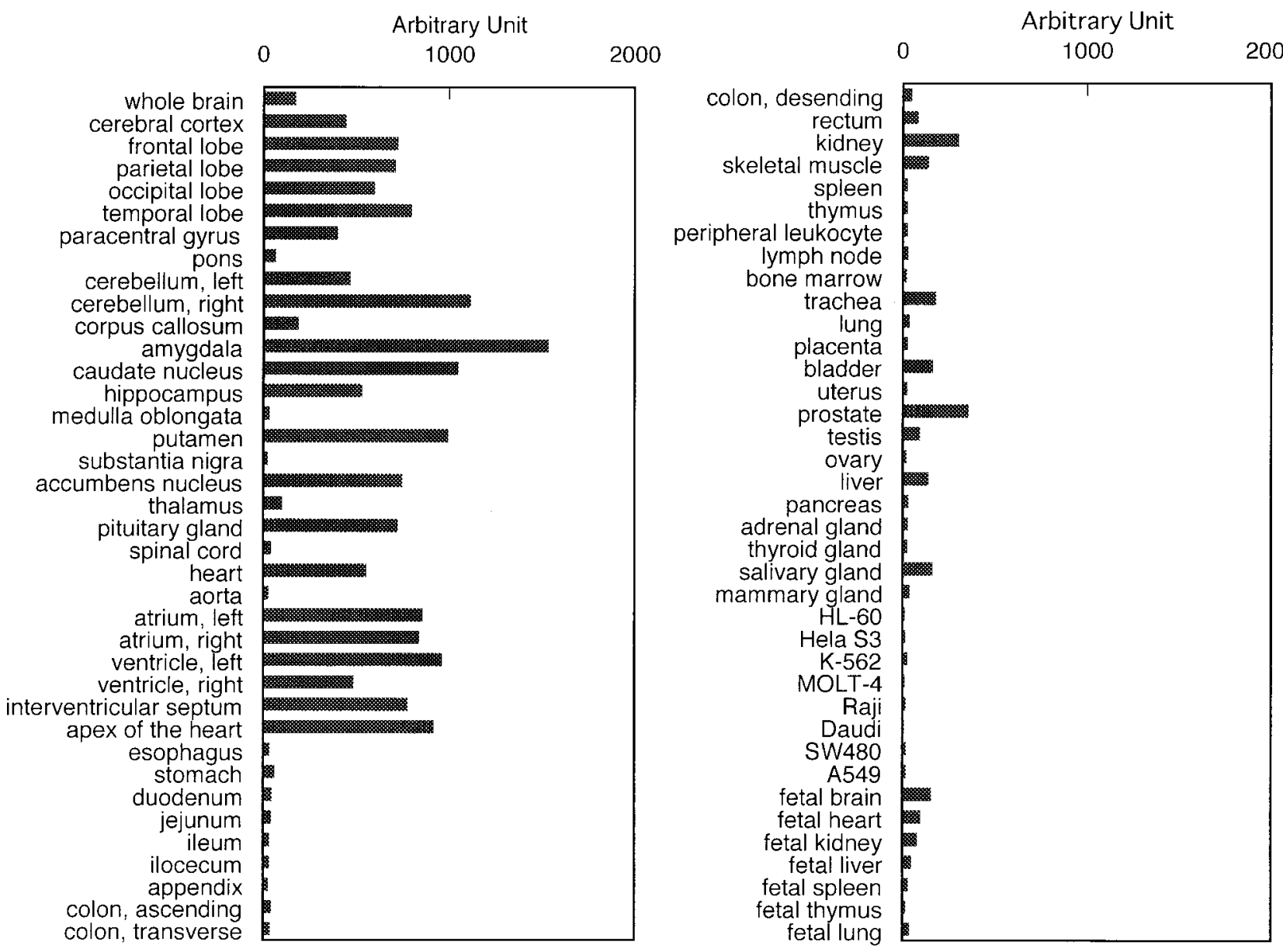

Figure 1 p38CTBP mRNA expression in human tissues. ${ }^{32}$ P-labeled p38CTBP cDNA was hybridized with the Human RNA Master Blot. Autoradiographic signals were quantitated by BAS-1500. Expression levels are expressed as arbitrary units. The expression in eight cancer cell lines is also shown.

p38CTBP in neural cells, we examined the staining of nuclei and p38CTBP-antibody complex with DAPI and rodamine-labeled anti-rabbit IgG respectively. Nuclei in neural and glial cells were stained by DAPI. The p38CTBP-antibody (CTBP168) complexes were also recognized by rodamine-labeled IgG. p38CTBP predominantly localized in cytoplasm in these cells (Fig. 4c and $d$ ).

Expression was mosaic in the internal layer and weak in Purkinje cells in cerebellum (Fig. 5a). Cytoplasmic staining was dominant in heart (Fig. 5c). In kidney, the expression was observed in renal tubules but not in glomerulus (Fig. 6a). Only a weak signal was observed in liver (Fig. 6c). The pancreatic islet cell was one of the p38CTBP-positive cells studied (Fig. 6e). By treatment of antibodies with $100 \mu \mathrm{g} / \mathrm{ml}$ of the peptide at $4{ }^{\circ} \mathrm{C}$ for $24 \mathrm{~h}$, the staining reaction was strongly reduced in each tissue (Figs 4b, 5b and d, 6b, d and f). However, the staining reaction was not affected by the treatment of the antibody with a non-specific peptide (data not shown).

\section{Discussion}

We previously identified CTBP in rat kidney and liver, and suggest that the CTBP plays roles in cellular storage and in nuclear transport of T3 in vitro (26). Expression of p38CTBP increased T3 content and suppressed T3-mediated transactivation in p38CTBPexpressing $\mathrm{GH} 3$ cells, suggesting that p38CTBP stores $\mathrm{T} 3$ and controls the T3-inducible transactivation in tissues (24). From these data, expression of p38CTBP probably plays crucial roles in stabilizing the T3-induced transactivity when extracellular T3 concentration alters physiologically or pathologically.

We prepared an anti-p38CTBP antibody which was obtained by immunization of a part of the amino acid sequence of p38CTBP. The antibody (CTBP168), which reacted with the GFP-coupled p38CTBP, specifically recognized radiolabeled native p38CTBP as demonstrated in the Results. We observed that the recognizing activity was inactivated by immunoadsorption with native p38CTBP prepared by the transfection 


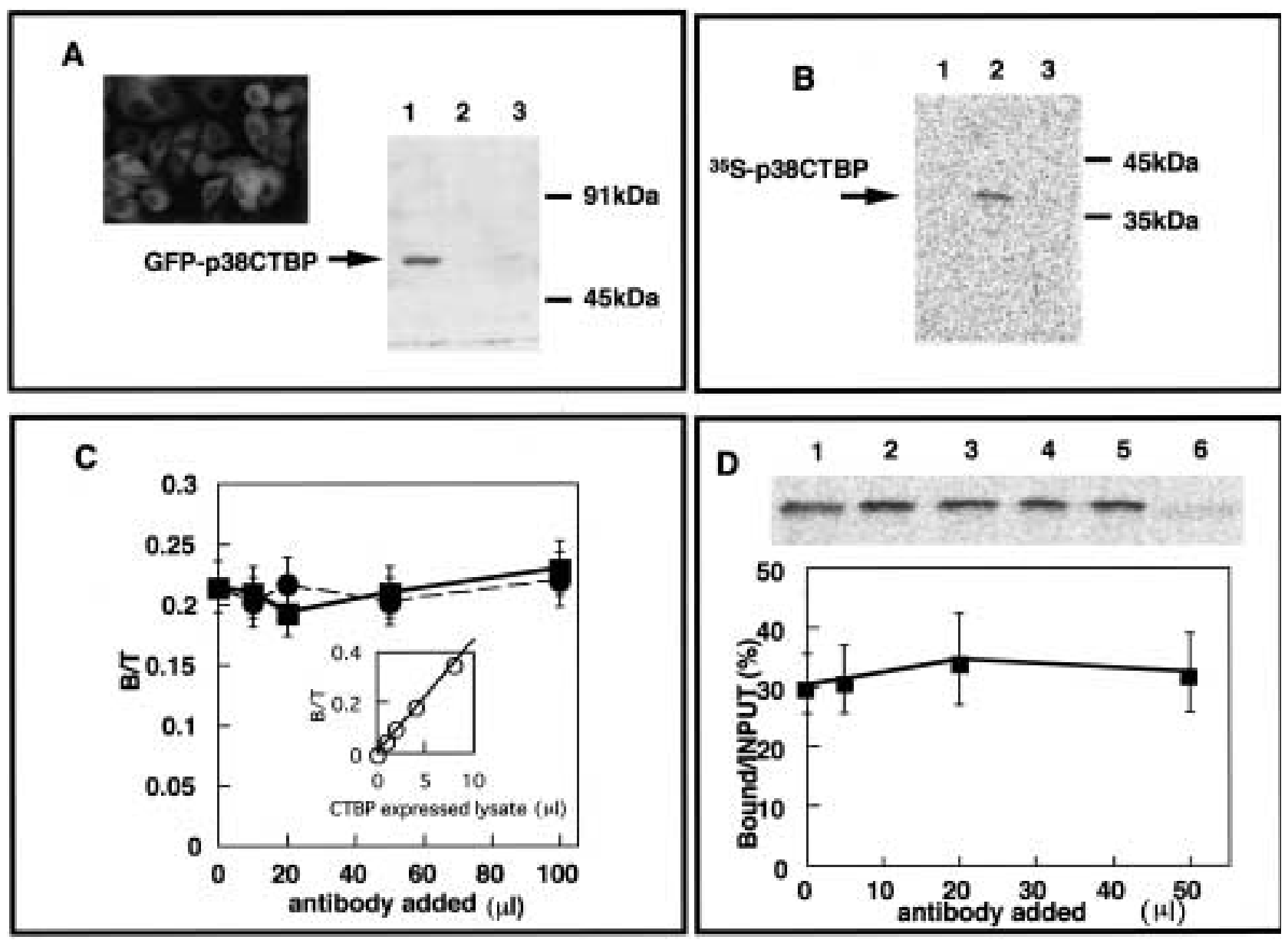

Figure 2 (A) Characterization of anti-p38CTBP antibody (CTBP168). Left panel: detection of GFP-tagged p38CTBP expressed in CPC45 cells. The fluoroscopic examination of GFP-tagged p38CTBP in CPC45 cells which were established from CHO-K1 cells as a cell line permanently expressing the fusion protein. CPC45 possessed NADPH-dependent T3-binding activity, while parental CHO-K1 did not. Cytoplasmic green fluorescent signal was detected in CPC45 but not in CHO-K1. Right panel: Western blotting analysis of GFP-p38CTBP. CPC45 or CHO-K1 was harvested with RIPA buffer. After freezing and thawing twice, the sample was centrifuged and the supernatant was boiled in SDS buffer. Aliquots $(10 \mu \mathrm{g})$ were applied onto a 10\% SDS-PAGE, and transferred to polyvinylidene difluoride membrane. CTBP168 (1:200 dilution) recognizes a $66 \mathrm{kDa}$ protein corresponding to GFP-p38CTBP expressed in CPC45 (lane 1), but the protein could not be identified in $\mathrm{CHO}-\mathrm{K} 1$ cell extract (lane 2). Antibody preadsorbed with the peptide did not recognize the protein which was prepared from CPC45 (lane 3). (B) Autoradiography of [ $\left.{ }^{35} \mathrm{~S}\right] \mathrm{p} 38 \mathrm{CTBP}$ expressed in reticulocyte lysate. One microliter of the $\left.{ }^{35} \mathrm{~S}\right]$ methionine-labeled translated product was incubated without antibody (lane 1), with $5 \mu \mathrm{g}$ CTBP168 (lane 2) or with the $5 \mu \mathrm{g}$ anti-Fas polyclonal antibody (lane 3) for $2 \mathrm{~h}$ at $4^{\circ} \mathrm{C}$ in $1 \mathrm{ml} \mathrm{TBSD}$ buffer. Mixtures were further incubated with $10 \mu \mathrm{l}$ protein $\mathrm{A}$ agarose for $1 \mathrm{~h}$. The resultant pellets were washed with TBSD and applied onto $12 \%$ SDS-PAGE. Autoradiographic visualization was carried out by BAS-1500. (C) Effect of CTBP168 on NADPH-dependent T3 binding. The inset shows the correlation between the amount of p38CTBP detected by antibody in reticulocyte lysate and $\left.{ }^{125} \mathrm{I}\right] \mathrm{T} 3$-specific binding, and a linear correlation was obtained. Five microliters of in vitro

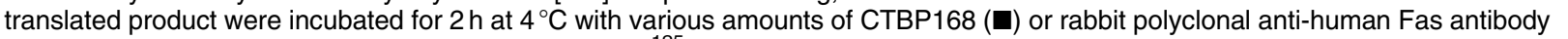
$(\bullet)$ as a negative control antibody in TBSD containing $\left[{ }^{125} \mathrm{l}\right] \mathrm{T} 3$ and $100 \mu \mathrm{M}$ NADPH. The concentration of CTBP $168 \mathrm{was} 0.9 \mathrm{mg} / \mathrm{ml}$ estimated by photometer. Two hours after the beginning of incubation, bound and free hormones were separated by dextran-coated charcoal. Each value indicates the mean \pm S.D. of triplicate determinations. B/T, bound/total radioactive ratio. (D) Effect of CTBP168 on homodimerizing activity of p38CTBP. Upper panel: GST-p38CTBP ( $6 \mu \mathrm{g}$ protein) immobilized on glutathione beads and ${ }^{35} \mathrm{~S}$-labeled p38CTBP synthesized in vitro were incubated without (lane 2) or with $5 \mu$ l (lane 3), $20 \mu$ l (lane 4) or $50 \mu$ l (lane 5) CTBP168 for $6 \mathrm{~h}$ at $4^{\circ} \mathrm{C}$. The concentration of CTBP 168 was $0.9 \mathrm{mg} / \mathrm{ml}$ estimated by photometer. GST immobilized on glutathione beads was incubated with ${ }^{35} \mathrm{~S}$-labeled p38CTBP as a negative control for $6 \mathrm{~h}$ at $4{ }^{\circ} \mathrm{C}$ (lane 6). Proteins bound to the washed beads were subjected to $12 \%$ SDS-PAGE, and followed by autoradiography. In the first lane, $20 \%$ of ${ }^{35}$ S-labeled p38CTBP alone was electrophoresed. Lower panel: results obtained in the upper panel were quantified by using an imaging analyzer (Fuji BAS-1500). The results are presented as the means \pm S.D. of each construct relative to the total labeled p38CTBP. An additional five independent experiments gave similar results.

of the cDNA of p38CTBP which has a T3-binding activity in the presence of NADPH. These results indicate that the antibody is available for the detection of native p38CTBP in Western blotting analysis and immunohistochemical studies.
p38CTBP has a high affinity for T3 binding in the presence of NADPH, and the protein has a sedimentation coefficient of $5.1 \mathrm{~S}$, a Stokes radius of $35 \AA$ and $76 \mathrm{kDa}$ (p76) of calculated molecular weight (11). The molecular mass estimated by SDS-PAGE, however, is 


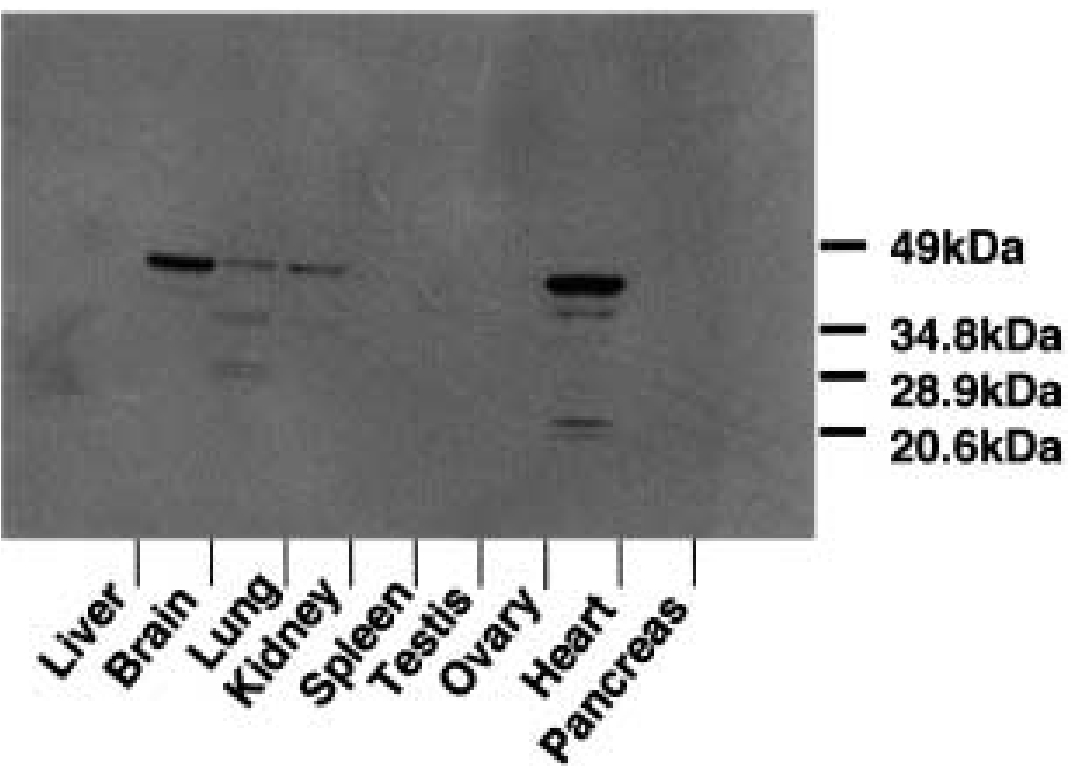

Figure 3 p38CTBP expression in adult human tissues. Multiple Tissue Blot Membrane (Geno Technology, St Louis, MO, USA) was blocked with TBS-T containing 5\% skim milk, and probed with anti-p38CTBP antibody (CTBP168) (diluted 1:200) in TBS-T containing $1 \%$ skim milk. Detection was performed by enhanced chemiluminescence using an HRP-conjugated mouse-anti-goat IgG antibody.

a

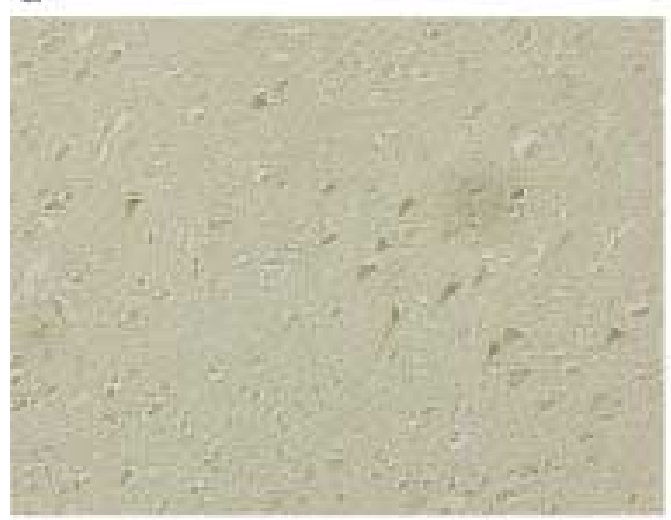

C

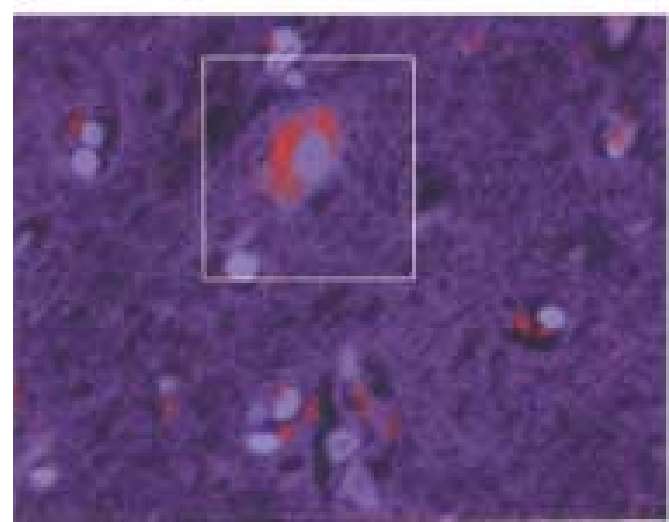

b

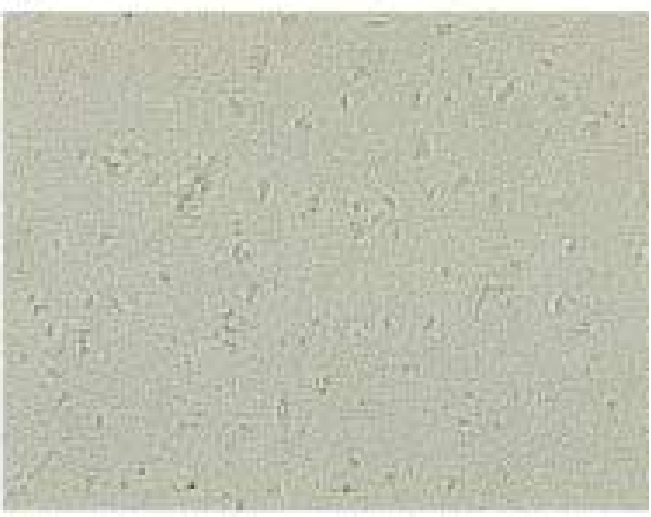

d

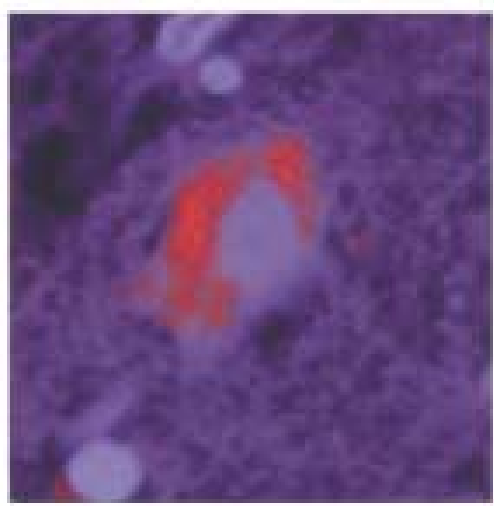

Figure 4 Immunostaining of p38CTBP in adult human cerebrum. Cerebrum prepared from the human was immunostained as described in Materials and methods. (a) Neural and some glia cells are stained. (b) Immunostainings using antibody fraction which was preadsorbed with the peptide. A section of cerebrum stained with DAPI and rodamine-antibody complex which recognized p38CTBP-CTBP168. (c) DAPI and rodamine were visualized with fluoroscopy. The boxed area is magnified in (d). 
a

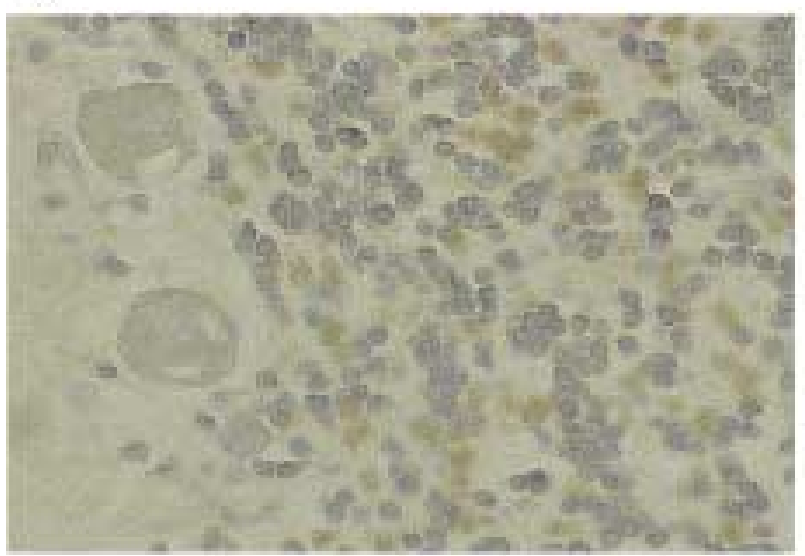

c

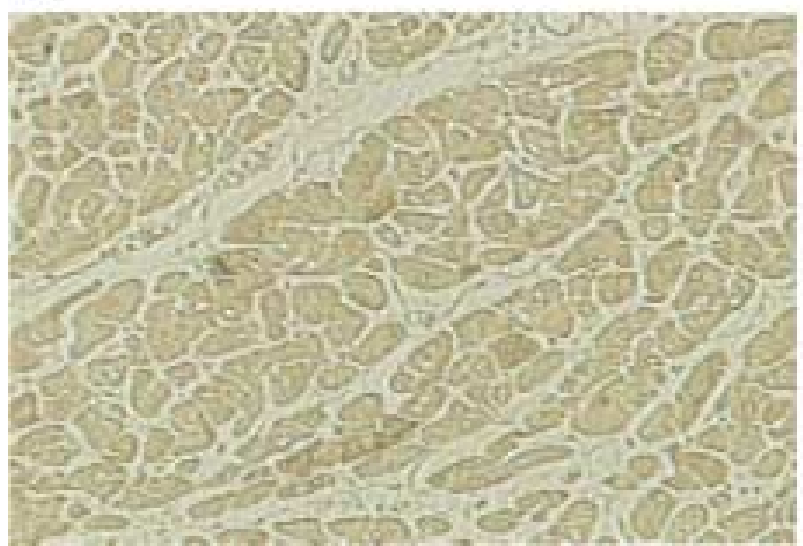

b

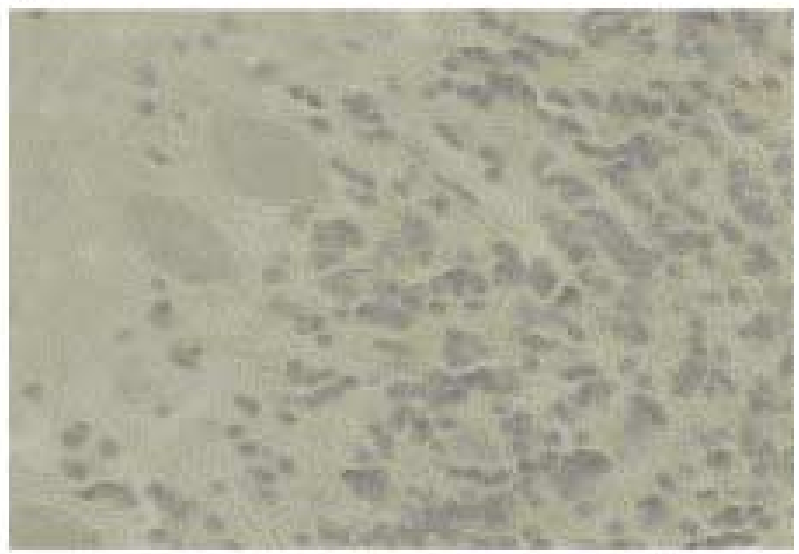

d

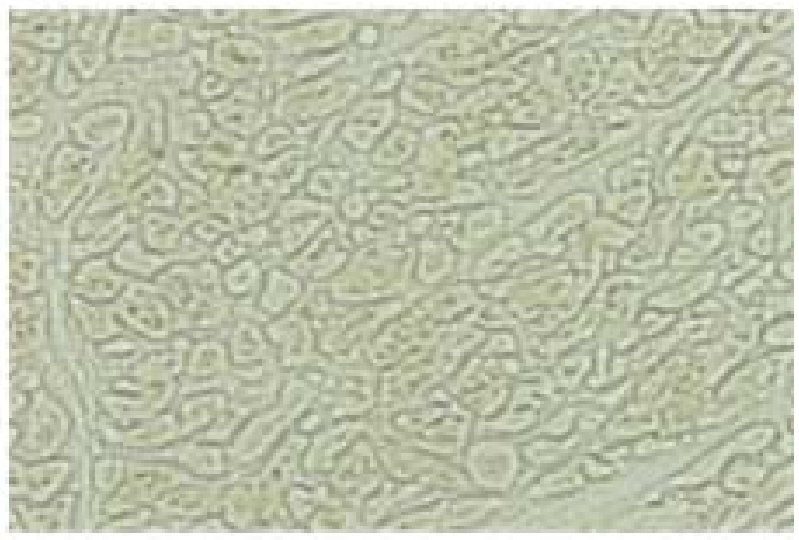

Figure 5 Immunostaining of p38CTBP in adult human cerebellum and heart. Cerebellum (a and b) and heart (c and d), were immunostained as described in Materials and methods. The internal layer is stained with a mosaic pattern, and Purkinje cells are weakly stained with the antibody (a). Homogeneous staining was observed in heart (c). (b and d) Immunostaining using an antibody fraction which was preadsorbed with the peptide. Nuclei were stained with hematoxylin in each preparation.

$38 \mathrm{kDa}(\mathrm{p} 38)$, suggesting that $\mathrm{p} 76 \mathrm{CTBP}$ is a homodimer of $\mathrm{p} 38 \mathrm{CTBP}(11)$. In order to evaluate whether the antibody interferes with NADPH-dependent T3 binding and dimerization, we examined the effect of CTBP168 on these activities. CTBP168 affected neither the T3 binding nor homodimerizing activities. These results indicate that the antibody can react with p38CTBP without modification of these important functions of this protein.

We examined the localization of p38CTBP in human tissues. Northern blotting in eight human tissues demonstrated that $\mathrm{p} 38 \mathrm{CTBP}$ is a single mRNA species (23). As shown in the Results, dot hybridization demonstrated that there is heterogeneous expression of p38CTBP in the central nervous system. Expression is high in cerebral cortex, cerebellum, amygdala, cauda nucleus, hippocampus, putamen and accumbens nucleus. However, expression in pons, corpus callosum, medulla oblongata, substantia nigra, thalamus and spinal cord is low. The expression of thyroid hormone receptors (TRs) is known to be heterogeneous in the central nervous system $(27,28)$. TR $\alpha 1$ is abundant in brain, heart, skeletal muscle and brown adipose cells $(29,30)$, whereas TR $\beta 1$ expression is more abundant (31), suggesting that p38CTBP appears to be expressed in tissues where TR $\alpha 1$ is abundantly expressed. However, the precise relationship between expressions of p38CTBP and TRs could not be resolved in this study.

p38CTBP was not expressed in the human cancer cell lines studied. The NADPH-dependent T3 binding, however, was measurable in rat hepatoma cell lines, dRLh (19), suggesting that the pathological role of p38CTBP expression remains to be characterized.

As has been observed, abundant p38CTBP was detected in brain and heart by immunohistochemical studies. In cerebrum, p38CTBP was predominantly expressed in the cytoplasm of both neural and glial cells. The nuclear expression level of p38CTBP may be too low to detect the immunofluoresence of the 
a

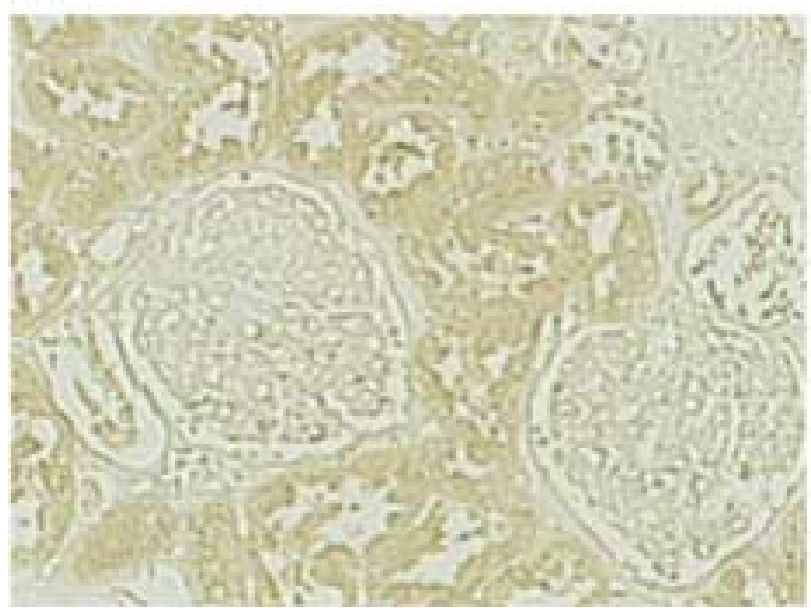

\section{C}

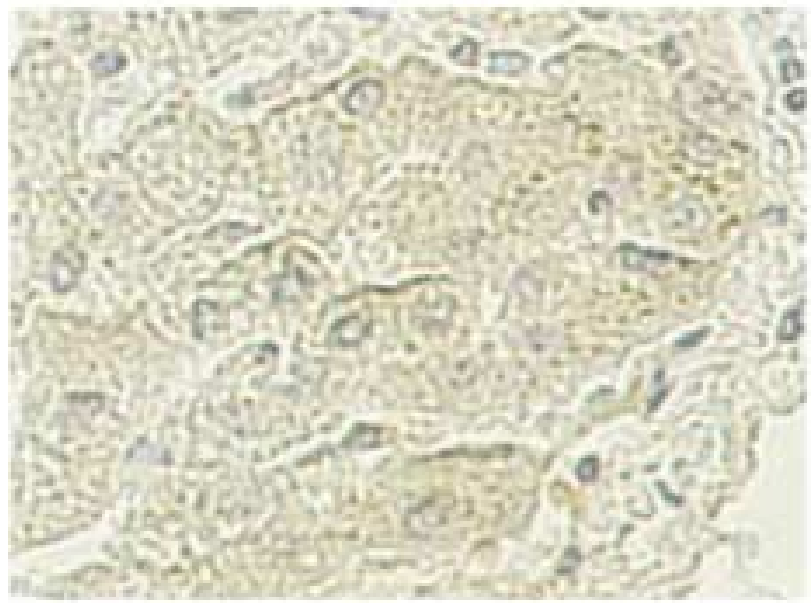

\section{e}

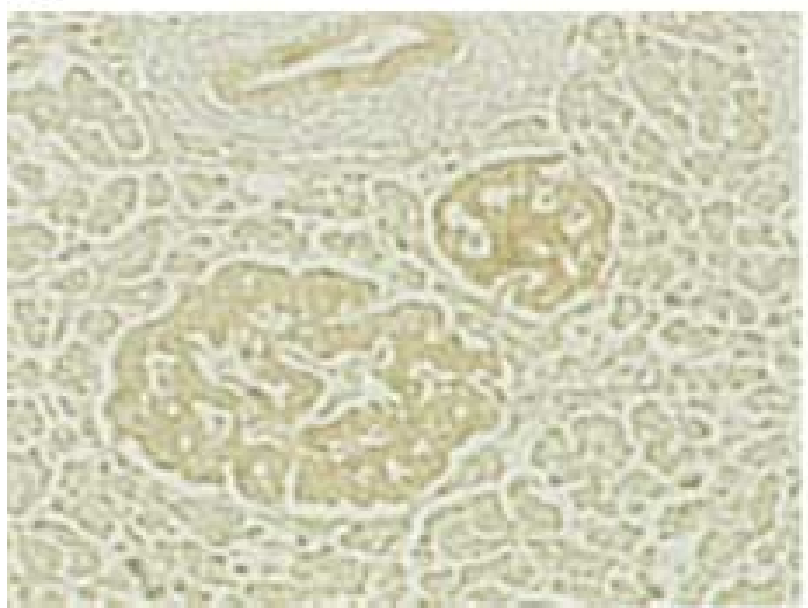

b

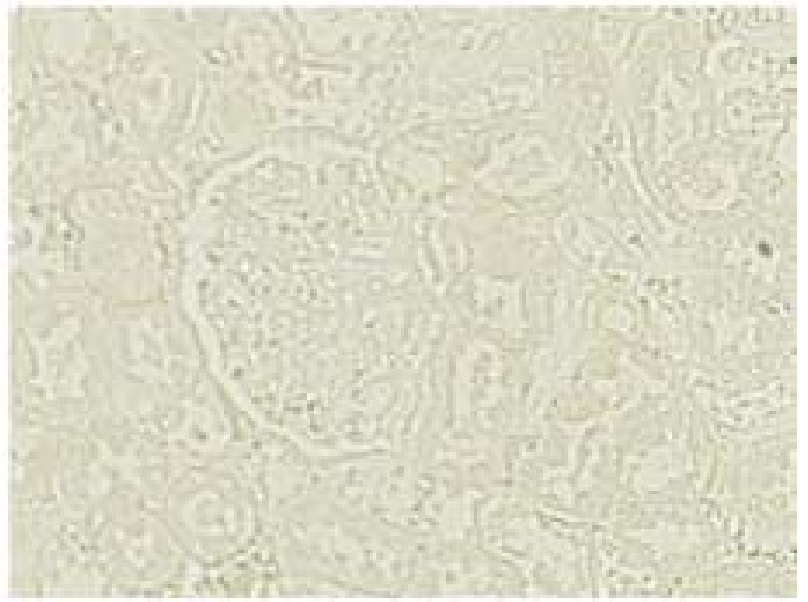

d

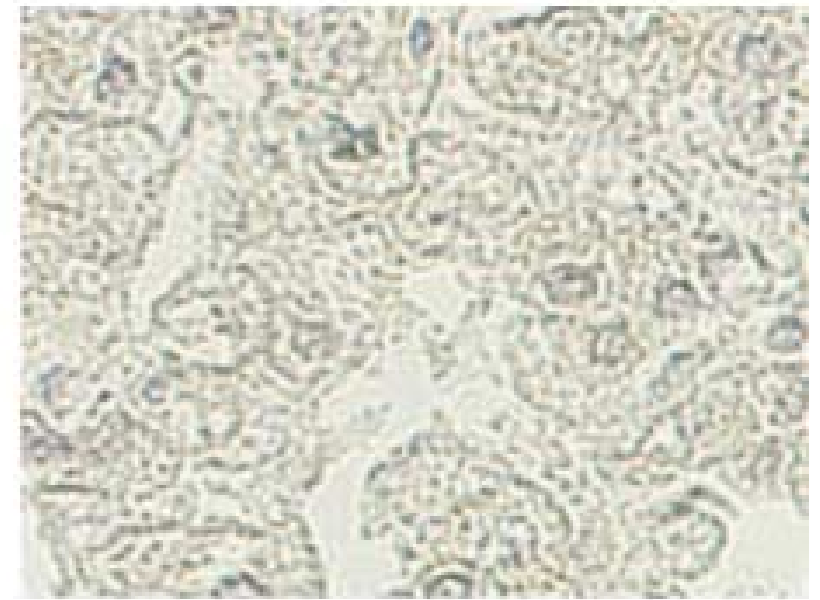

f

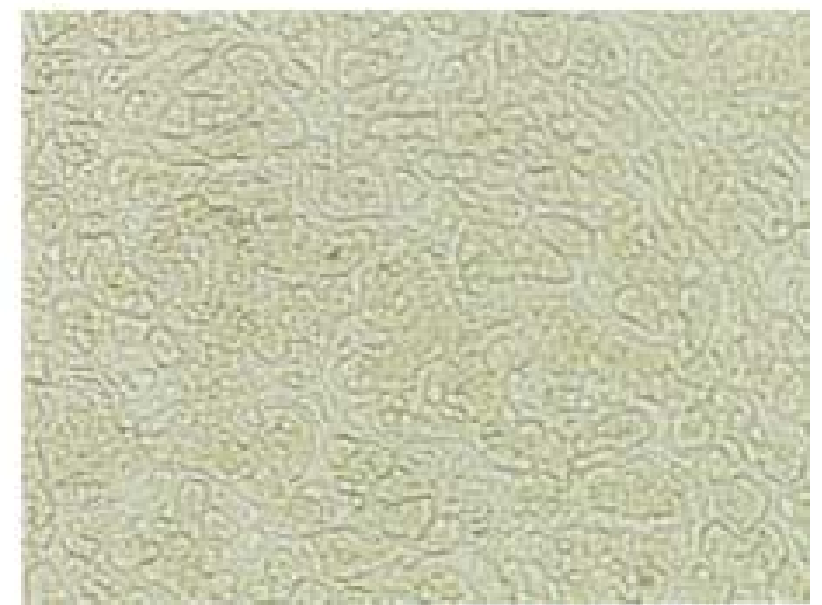

Figure 6 Immunostaining of p38CTBP in adult human kidney, liver and pancreas. Kidney ( $a$ and b), liver (c and d), and pancreas (e and f) were immunostained as described in Materials and methods. (a) Renal tubules but not glomerular cells are stained. (c) Weak staining is observed in liver. (e) Islet but not exocrine cells are stained with the antibody. Immunostainings using antibody fraction which was preadsorbed with the peptide are shown in $b, d$ and $f$. 
antibody in nuclei, since we observed that a part of the CTBP could be transported into nuclei and that acceptor protein for CTBP is present in nuclei as previously reported $(7,9)$. The study showed cellspecific localization of p38CTBP in the inner layer of cerebellum. Granule cells were specifically, but not homogeneously, stained with the antibody. This mosaic staining of granule cells may reflect the presence of a sub-population of granule cells (32). Cell-specific localization of p38CTBP was also observed in other tissues. Tubular but not glomerular cells in kidney, and islet but not exocrine cells in pancreas were stained with the antibody, suggesting that strictly controlled cell-specific expression must be present.

In this study, by estimating the expression of p38CTBP, we have demonstrated that p38CTBP is preferentially expressed in human brain and heart, and that cell-specific p38CTBP expression is present. While the cell-specific distribution of p38CTBP may play important roles in the cell-specific regulation of thyroid hormone action, the precise physiological function of p38CTBP remains to be elucidated.

\section{Acknowledgement}

We thank Ms Tomoko Nishizawa for her technical assistance.

\section{References}

1 Larsen PR, Davis TF \& Hay ID. The thyroid gland. In Williams' Textbook of Endocrinology, edn 9, ch 11, pp 389-515. Eds JD Wilson, DW Foster, HM Kronenberg \& PR Larsen. Philadelphia: WB Saunders, 1998.

2 Lazar MA. Thyroid hormone receptors: multiple forms, multiple possibilities. Endocrine Reviews 199314 184-193.

3 Lein A \& Dowben RM. Uptake and binding of thyroxine and triiodothyronine by rat diaphragm in vitro. American Journal of Physiology $19612001029-1032$.

4 Eckel J, Rao GS, Rao ML \& Breuer H. Uptake of L-triiodothyronine by isolated rat liver cells. Biochemical Journal 1979182 473-491.

5 Friesema EC, Docter R, Moerings EP, Stieger B, Hagenbuch B, Meier PJ et al. Identification of thyroid hormone transporters. Biochemical and Biophysical Research Communications 1999254 497-501.

6 Hashizume K, Miyamoto T, Ichikawa K, Yamauchi K, Kobayashi M, Sakurai A et al. Purification and characterization of NADPH-dependent cytosolic 3,5,3'-triiodo-L-thyronine binding protein in rat kidney. Journal of Biological Chemistry $1989 \mathbf{2 6 4}$ 4857-4863.

7 Hashizume K, Miyamoto T, Ichikawa K, Yamauchi K, Sakurai A, Ohtsuka $\mathrm{H}$ et al. Evidence for the presence of two active forms of cytosolic 3,5,3'-triiodo-L-thyronine (T3)-binding protein (CTBP) in rat kidney. Specialized functions of two CTBPs in intracellular T3 translocation. Journal of Biological Chemistry $1989 \mathbf{2 6 4}$ $4864-4871$.

8 Hashizume K, Miyamoto T, Yamauchi K, Ichikawa K, Kobayashi M, Ohtsuka $\mathrm{H}$ et al. Counterregulation of nuclear 3,5,3'-triiodo-L-thyronine (T3) binding by oxidized and reducednicotinamide adenine dinucleotide phosphates in the presence of cytosolic T3-binding protein in vitro. Endocrinology $1989 \mathbf{1 2 4}$ $1678-1683$.
9 Hashizume K, Miyamoto T, Kobayashi M, Suzuki S, Ichikawa K, Yamauchi K et al. Cytosolic 3,5,3'-triiodo-L-thyronine (T3)-binding protein (CTBP) regulation of nuclear T3 binding: evidence for the presence of T3-CTBP complex-binding sites in nuclei. Endocrinology 1989124 2851-2856.

10 Hashizume K, Suzuki S, Ichikawa K \& Takeda T. Purification of cytosolic 3,5,3'-triiodo-L-thyronine (T3)-binding protein (CTBP) which regulates nuclear T3 translocation. Biochemical and Biophysical Research Communications 1991174 1084-1089.

11 Kobayashi M, Hashizume K, Suzuki S, Ichikawa K \& Takeda T. A novel NADPH-dependent cytosolic 3,5,3'-triiodo-L-thyroninebinding protein (CTBP; 5.1S) in rat liver: a comparison with 4.7S NADPH-dependent CTBP. Endocrinology $1991 \quad 129$ 1701-1708.

12 Suzuki S, Hashizume K, Ichikawa K \& Takeda T. Ontogenesis of the high affinity NADPH-dependent cytosolic 3,5,3'-triiodoL-thyronine-binding protein in rat. Endocrinology 1991129 $2571-2574$.

13 Aoki N, Ito K \& Ito M. $\mu$-crysttallin, thyroid hormone-binding protein, is expressed abundantly in the murine inner root sheath cells. Journal of Investigative Dermatology $2000115402-405$.

14 Nishii Y, Hashizume K, Ichikawa K, Miyamoto T, Suzuki S, Takeda $\mathrm{T}$ et al. Changes in cytosolic 3,5,3'-tri-iodo-L-thyronine (T3) binding activity during administration of L-thyroxine to thyroidectomized rats: cytosolic T3-binding protein and its activator act as intracellular regulators for nuclear T3 binding. Journal of Endocrinology 1989123 99-104.

15 Nishii Y, Hashizume K, Ichikawa K, Takeda T, Kobayashi M, Nagasawa T et al. Induction of cytosolic triiodo-L-thyronine (T3) binding protein (CTBP) by T3 in primary cultured rat hepatocytes. Endocrine Journal 199340 399-404.

16 Hashizume K, Suzuki S, Ichikawa K, Takeda T \& Kobayashi M. Effect of active vitamin D3 on the levels of NADPH-dependent cytosolic 3,5,3'-triiodo-L-thyronine-binding protein. Biochemical and Biophysical Research Communications 1991177 388-394.

17 Takeda T, Ichikawa K, Kobayashi M, Miyamoto T, Suzuki S, Nishii Y et al. Response of hepatic proteins to 3,5,3'-tri-iodoL-thyronine in diabetic rats. Journal of Endocrinology 1994143 $55-63$.

18 Dieudonne SC, Kerr JM, Xu T, Sommer B, DeRubeis AR, Kuznetsov SA et al. Differential display of human marrow stromal cells reveals unique mRNA expression patterns in response to dexamethasone. Journal of Cellular Biochemistry 199976 231-243.

19 Ichikawa K, Hashizume K, Kobayashi M, Nishii Y, Ohtsuka H, Suzuki S et al. Heat shock decreases nuclear transport of 3,5,3'triiodo-L-thyronine in clone 9 cells. Endocrinology $1992 \mathbf{1 3 0}$ 2317-2324.

20 Ichikawa K \& Hashizume K. Cellular binding proteins of thyroid hormones. Life Sciences 199149 1513-1522.

21 Vie MP, Evrard C, Osty J, Breton-Gilet A, Blanchet P, Pomerance M et al. Purification, molecular cloning, and functional expression of the human nicodinamide-adenine dinucleotide phosphate-regulated thyroid hormone-binding protein. Molecular Endocrinology $1997111728-1736$.

22 Wistow G \& Kim H. Lens protein expression in mammals: taxonspecificity and the recruitment of crystallins. Journal of Molecular Evolution 199132 262-269.

23 Kim RY, Gasser R \& Wistow GJ. $\mu$-crystallin is a mammalian homologue of Agrobacterium ornithine cyclodeaminase and is expressed in human retina. PNAS $1992899292-9296$.

24 Mori J, Suzuki S, Kobayashi M, Inagaki T, Komatsu A, Takeda T et al. Nicotinamide adenine dinucleotide phosphate-dependent cytosolic T3 binding protein as a regulator for T3-mediated transactivation. Endocrinology $2002 \mathbf{1 4 3} 1538-1544$.

25 Kakizawa T, Miyamoto T, Ichikawa K, Kaneko A, Suzuki S, Hara M et al. Functional characterization between oct-1 and retinoid x receptor. Journal of Biological Chemistry 1999274 19103-19108.

26 Hashizume K, Kobayashi M \& Miyamoto T. Active and inactive forms of $3,5,3^{\prime}$-triiodo-L-thyronine (T3)-binding protein in rat kidney cytosol: possible role of nicotinamide adenine dinucleotide 
phosphate in activation of T3 binding. Endocrinology 1986119 $710-719$.

27 Forrest D, Sjoberg M \& Vennstrom B. Contrasting developmental and tissue-specific expression of a and $\mathrm{b}$ thyroid hormone receptor genes. EMBO Journal 19909 1519-1528.

28 Bradley DJ, Towle HC \& Young WS III. Spatial and temporal expression of $\alpha$ - and $\beta$ - thyroid hormone receptor mRNAs, including the $\beta 2$-subtype, in the developing mammalian nervous system. Journal of Neuroscience 199212 2288-2302.

29 Mitsuhashi T, Tennyson GE \& Nikodem VM. Alternative splicing generates messages encoding rat c-erbA proteins that do not bind thyroid hormone. PNAS $1988 \mathbf{8 5} 5804-5808$.

30 Falcone M, Miyamoto T, Fierro-Renoy F, Macchia E \& DeGroot LJ. Antipeptide polyclonal antibodies specifically recognize each human thyroid hormone receptor isoform. Endocrinology 1992 $1312419-2429$.

31 Koenig R, Warne RI, Brent GA, Harney JW, Larsen PR \& Moore DD. Isolation of a cDNA clone encoding a biologically active thyroid hormone receptor. PNAS $1988 \mathbf{8 5}$ 5031-5035.

32 Mellor JR, Merlo D, Jones A, Wisden W \& Randall AD. Mouse cerebellar granule cell differentiation: electrical activity regulates the GABAA receptor alpha 6 subunit gene. Journal of Neuroscience $1998182822-2833$.

Received 21 August 2002

Accepted 4 November 2002 